Article

\title{
Inclusion in Physical Education: Perceptions of Irish and Swiss Student Teachers Following Participation in a European Exchange Programme
}

\author{
Susan Marron ${ }^{1}$ and Sonia Morris ${ }^{2, *}$ \\ Received: 21 ${ }^{\text {st }}$ November 2017; Accepted: 10 ${ }^{\text {th }}$ January 2018; Published: 4 November 2018
}

\begin{abstract}
This study focused on inclusion in physical education (PE) and investigated, using the theory of planned behaviour, how a teacher education exchange programme across two European countries: (i) influenced the attitudes of student teachers (ST) towards inclusion; (ii) critically challenged the subjective norm; and (iii) impacted on the confidence of STs towards inclusive practice in PE lessons. The methodology used was qualitative and included focus group interviews $(n=6)$ and reflective reports. Four themes emerged from a thematic analysis of the data: (i) understandings of inclusion in mainstream PE; (ii) learned methods of including children with special educational needs (SEN) in mainstream PE; (iii) perceived barriers to inclusive practice; and (iv) the important role of professionals in inclusion. Teaching education universities should be mindful of the expectations and practices with regards to inclusion within their respective countries and provide opportunities for STs to critically question subjective and behavioural norms. A cultural exchange is recommended as a proposed teaching methodology at teacher education based on the findings of this study. The opportunity to compare inclusive practice in two different countries brought the subjective norm into consciousness for participants in this study and facilitated critical questioning of this norm. Findings highlight the benefits to including intercultural opportunities into teacher education specifically for PE teachers.
\end{abstract}

Keywords: Special educational needs; inclusion; universal design; differentiation; European exchange; theory of planned behaviour

\section{Introduction}

The inclusion of children with special educational needs (SEN) in mainstream education has gained international acceptance and has been increasingly a focus of national and international policy on education (Crawford, O'Reilly \& Flanagan, 2012; Gasser, Malti \& Buholzer, 2014; Haegele \& Sutherland, 2015). Consequently, there has been an increase in the number of children with SEN being educated in mainstream settings (Meegan \& MacPhail, 2006). In this article, we will focus on student teacher (ST) perspectives of schools' inclusive practices in physical education (PE) lessons in two European countries, Ireland and Switzerland. We will first define SEN and inclusion, and then provide a brief overview of the literature on inclusive practice in schools. Teacher education and how inclusive practices in PE are encouraged for STs will be outlined.

\section{Definition of SEN and inclusion}

For the purposes of this article, children with special educational needs (SEN) refer to those children with particular learning needs that arise from a range of differences compared to typical children, including cognitive, physical, sensory, communicative and/or behavioural. Inclusion is a means of increasing participation in learning by all children in order that their educational needs can be met and refers to a process that must remove all forms of exclusionary practice (Fitzgerald, Stride \& Jobling, 2012; Florian \& Rouse, 2009). Inclusion can be considered the development of strategies 
that bring about a genuine equalisation of opportunity (UNESCO, 1994). There is no universally accepted definition of inclusion, yet it is generally accepted in the literature that inclusion goes beyond providing access into mainstream schools, making adjustments and assumptions about abilities. Inclusion of children with SEN is encouraged in mainstream schools where appropriate and feasible with as little segregation as possible in Ireland since the 1990's (Department of Education and Skills, 1993) and since 2012 in the State of Vaud, Switzerland.

\section{Inclusive practice in schools}

The literature describing inclusive practices in schools has highlighted a bias towards 'placing' rather than 'including' in schools and curricula developed for children with typical abilities (Smith \& Green, 2004). Children with SEN are expected to fit into existing structures. This practice of differentiation is not about drastically changing the content of a lesson, but about providing alternative pathways and additional support to achieve common learning goals (Department of Education and Science, 1999) More recent reports suggest that inclusive practice in schools is achieved through a process of universal design which advocates designing a curriculum from the bottom up. This approach is flexible to suit all learners, meaning the learning activities and resources adopted are accessible to a diverse range of abilities (Winter \& $\mathrm{O}^{\prime}$ Raw, 2010). Universally designed instructional programmes and environments work for all children, to the greatest extent possible, without the need for adaptation or specialised design (Fitzgerald, 2011; Hardman, 2009;). This method of inclusion requires teachers to develop ways to fully include children with SEN in school, but which also benefit everybody (Etienne, Parkinson \& Verkest, 2005).

Differences in educational opportunities for children can depend not only on their individual circumstances, but also on where they live and the way in which educational systems are structured, regulated and supported in their home country (Florian \& Rouse, 2009). Furthermore, Nash and Norwich (2010) highlight the tendency for teacher education to reflect the national policy and provisions made for children with SEN which tends to fall short of universal design.

\section{Teacher education and inclusive practices in physical education}

Both the Irish primary PE teacher guidelines on inclusive practice (Department of Education and Skills, 1999) and the school law in State Vaud in Switzerland (Chapitre IX Pédagogie différenciée Art. 98 , 2011) recommend teachers to adapt the environment, equipment, and activities when teaching PE to children with SEN. This suggests a culture in support of differentiation in practice for PE. The education and the aptitude of the teacher to accommodate for pupils with SEN is vital for the implementation of any successful PE programme (Block, 2007; Crawford, O'Reilly \& Flanagan, 2012).

In Ireland inclusive PE practice at initial teacher education has been a relatively new phenomenon (Tindall, MacDonald, Carroll \& Moody, 2015). Teaching methodologies for the instruction of STs in inclusive PE practice supported by the literature include: the lived learning experience (Crawford et al., 2012; Tindall et al., 2015) which includes off-campus immersive location work (Crawford et al., 2012; Meyers \& Lester, 2013) and exposure to practical hands on experiences with children with SEN; well-planned coursework (Piletic \& Davis, 2010; Rust \& Sinelnikov, 2010); and peer-tutoring and cooperative learning (Qi \& Ha, 2012). Fitzgerald (1999) cautions that these teaching methodologies must also be supported by positive attitudes and meaning. It is therefore concerning that Marron, Murphy and O'Keeffe (2013) found that STs reported finding inclusive PE lessons challenging when on placement as well as experiencing a lack of support. This suggests that many STs leave initial teacher education with a negative attitude towards inclusion.

\section{Teachers intentions, attitudes and behaviours}

The theory of planned behaviour (TPB; Ajzen \& Fishbein, 1980; Fishbein \& Ajzen, 1975) has been used in the PE literature to explore the link between teachers' intentions to include children with SEN in PE lessons with their attitudes towards inclusion, the subjective norm of inclusion, and their perceived ability to perform this behaviour (Jeong \& Block, 2011). All components of the TPB are 
important determinants of actual behaviour. This model provides insight into teachers' concerns toward, and beliefs relating to resources and supports necessary for, inclusion in PE.

The literature suggests that although teachers (Avramidis \& Norwich, 2002), STs (Cardona, 2009), and more specifically PE teachers (Hodge, Ammah, Casebolt, LaMaster \& O'Sullivan, 2004) have positive attitudes towards the idea of inclusion, they also report feeling unprepared to implement inclusive practices. Initial teacher education provides the opportunity to further prepare STs for inclusion in general classes and PE lessons more specifically.

Research suggests that a combination of formal instruction of teaching methods followed by direct contact with those with SEN can alter attitudes towards the practice of inclusion in a favourable direction (Avramidis \& Norwich, 2002; Taliaferro, Hammond \& Wyant, 2015). Vickerman and Coates (2009) suggest listening to the voice of ST and newly qualified teachers. They believe that despite the prominence of inclusion at statutory and political agenda and the increased focus of inclusion in schools, there is limited empirical research on the experiences of trainee and recently qualified teachers related to the development of their learning and understanding and application of strategies to include children with SEN. A call is made for teacher providers to review their current systems and establish a clear context as to what inclusive PE for children with SEN means in practice. They believe that inclusion should permeate initial teacher education courses and provide sound pedagogical guidance and knowledge to STs to ease their fears regarding SEN. As well as embedding inclusion across modules, the amount of time devoted to considering issues as well as opportunities related to SEN was believed to influence the attitudes of STs. On the other-hand it is acknowledged that SEN is only one of many concepts that must be achieved in a teacher education programme.

This study adds to the limited voice of STs. We explored changes in the perceptions of Swiss and Irish STs following a European exchange programme, which included an instructional component and direct observation of inclusive PE lessons. A further purpose of this study was to inform the work of PE teacher educators. From this study, we highlight the importance of maximising opportunities to expose STs to inclusion to impact in-service inclusive practices. In this qualitative study, we will focus on the three component parts of the TPB by exploring: (1) attitude changes of STs towards inclusion in PE resulting from the exchange; (2) the subjective norm component by focusing on the differences in the attitudes of Swiss and Irish STs towards inclusive practice in PE; and (3) potential barriers and incentives to inclusive behaviour. We aim to provide insight into potential learning opportunities for STs to facilitate the future inclusion of all children in PE lessons.

\section{Materials and Methods}

\section{Background}

This study was initiated by an invitation from a Swiss university to become a partner in their initiative to compare and contrast practices between two European universities under the Projets d'Equipe d'Ensignants-Chercheurs et d' etudiants en Reseaux Sociaux (PEERS) programme. PEERS is a ST and researcher social network project funded by the Swiss Government with the aim of encouraging international mobility of both teacher educators and STs to improve education and research. Its objectives are: (i) to consolidate a research network: and (ii) to prepare STs to be global teachers in a global world. A PEERS programme runs for one academic year with two one-week visits to each of the two universities. Key components of this PEERS project can be read in Table 1. In brief, the exchange programme elements were designed to include presentations, group meetings to discuss the topic being examined, attendance at university lectures and observation of PE lessons in school settings. Observations involved STs watching the lessons from the side of the gymnasium or the field areas if outdoors. Sometimes the class teachers requested the STs to participate and to assist the children. 


\section{Communications}

English language with the STs and French and English with the teacher educators via Email, Skype, Dropbox

\section{Exchange Week Components}

- Autumn week and spring week in each university with student teacher to student teacher accommodation.

- Attendance at physical education practical seminars \& lectures on SEN at both universities with a focus on inclusion. More information is available from the authors on request.

- Mainstream primary \& secondary schools' physical education lesson observations (two

Dublin and three Lausanne school visits) conducted through English in Dublin and French in Switzerland. STs and teacher educators translated when required. One Irish school was selected as it had won the CARA National Inclusion Education award in 2014. Another school visited was a filter mainstream secondary school for young people with visual impairments. In the canton of Vaud, the schools visited were known to the lecturer for their inclusion practices of children with physical disabilities. All schools chosen to visit had to be within reach either by walking or with public transport.

- Three focus group interviews \& three reflection meetings (at the beginning and the end of the Dublin autumn visit and the final one at the end of the Swiss visit in the spring)

- Distribution of key readings on inclusive practice in PE to support lesson observations (available from authors on request)

- Cultural visits \& social events

\begin{tabular}{cc}
\hline \multicolumn{1}{c}{ Reports } \\
\hline$\bullet \quad$ Written individualised reflective report (Irish) \\
$\bullet \quad$ Written collaborative report (Swiss) \\
\hline
\end{tabular}

\section{Participants and setting}

The sample was a convenience sample. The universities had different recruitment processes due to different pathways. There were restrictions to the Irish University teaching programme at the time of the PEERs project. It was moving from a three to a four-year track programme. The PEERS opportunity was offered to second year generalist primary STs majoring in PE who were the first cohort on the four-year programme. An email was sent to this major specialism group explaining the project with an offer of three places. Three students replied to the call and these three were accepted. Swiss Masters STs in the participating Swiss university were informed with a call on the university web page and with a follow-up information session. Emails were also sent to all enrolled STs. Each prospective Swiss ST presented their interest in the PEERS project to their chosen courses i.e. Physical Education. Table 2 highlights the contextual differences between the participants including age, nature of degree, stage of study, and course requirements. The differences in cohorts were due largely to different university systems resulting in the bespoke nature of the PEERS project. The study resulted in six participants $(n=6)$.

\section{Data collection}

Three focus groups were conducted by the two project leads (one Irish and one Swiss lecturer) over the course of two exchange visits, one in the autumn and one in spring. There was no pilot study due to the brevity of the exchange and the emergence of the research study. The participants signed consent to participate. Each interview was conducted through English and lasted between 20 and 40 minutes. The first interview on day one of the autumn visit, which took place in Ireland, included questions relating to demographic information, understandings of inclusion, and more specifically inclusion in PE. The latter two focus groups (one at the completion of the autumn Irish visit and one at the completion of the Swiss spring visit) focused on ST reflections of their experiences with regards 
to inclusion of children with SEN in PE. Transcripts were emailed to the participants for their approval to ensure accurate representation.

Table 2. Contextual Information

\begin{tabular}{|c|c|c|}
\hline & \multicolumn{2}{|c|}{ Nationality } \\
\hline & Irish & Swiss \\
\hline Number of Student Teachers & 3 & 3 \\
\hline Stage of Study & 2nd Year Undergraduate & $\begin{array}{l}\text { Master's in Education with an } \\
\text { undergraduate Sports Science } \\
\text { (Obligatory pathway) }\end{array}$ \\
\hline Type of Degree & $\begin{array}{l}\text { Primary Generalist Teachers } \\
\text { (aged 4-12 years) with a Major } \\
\text { Specialism in PE }\end{array}$ & $\begin{array}{c}\text { Graduate Specialist Teachers } \\
\text { of Physical Education (aged } \\
10-16 \text { years) }\end{array}$ \\
\hline Age & 19 & $25-29$ \\
\hline Inclusion Teaching & $\begin{array}{c}\text { Inclusion Module (24hrs of } \\
\text { lectures) }\end{array}$ & $2 \times 3$ hrs lectures on Inclusion \\
\hline $\begin{array}{c}\text { Assessment Requirements } \\
\text { European Credit Transfers } \\
\text { (ECTs) }\end{array}$ & $\begin{array}{c}\text { Individualised Reflective } \\
\text { Report } \\
\text { (0 ECTs) }\end{array}$ & $\begin{array}{c}\text { Collaborative Written Report } \\
\text { (6 ECTs) }\end{array}$ \\
\hline $\begin{array}{l}\text { Experience of Teaching } \\
\text { Children with SEN }\end{array}$ & \multicolumn{2}{|c|}{$\begin{array}{l}\text { Two Swiss student teachers (SS1 and SS2) had no experience of } \\
\text { including children with SEN in their PE lessons. One Swiss } \\
\text { student (SS3) had an Adapted Physical Activity certificate for } \\
\text { teaching in special schools with some experience. The three } \\
\text { Irish students (IS1, IS2 and IS3) had experienced children with } \\
\text { Attention Deficit Hyperactivity Disorder (ADHD) on school } \\
\text { placement in their first year of studies. }\end{array}$} \\
\hline
\end{tabular}

The three focus-groups are referenced in the findings as FG1 (commencement of Irish visit), FG2 (at the conclusion of Irish visit) and FG3 (at the conclusion of the Swiss visit). Pseudonyms are used for all participants to ensure confidentiality, and are referenced as SS1, SS2 and SS3 (Swiss ST one, two, and three respectively), and IS1, IS2 and IS3 (Irish ST one, two and three respectively).

\section{Participant reflective reports}

Participants submitted reports on their experience of the exchange as set by their home University. The requirement by the Irish University for their participants was an individual reflective report of their time in Switzerland, referenced as ISR IS1, ISR IS2 and ISR IS3 (Irish ST report for Irish ST one, two and three respectively). Swiss participants were required by their University to write a collaborative report (in English) on their experiences in Ireland, referenced as SSR (Swiss ST report). The Swiss received six European Credit Transfers for their participation in the PEERS programme on completion of this formal assignment. The Irish STs participated without receiving formal credits. Permission was obtained from each participant to use these reports to support the focus group data.

\section{Data analysis}

Focus group transcripts were analysed by the Irish lecturer and the second author of this paper, using thematic analysis, with themes relating to inclusion in PE emerging from the data after a process of coding, re-coding until theme saturation and then categorising. Participant reports were used to support the themes generated from the focus group data. 


\section{Results}

This study explored the changing perceptions of STs to inclusive practice in PE as they engaged in a European exchange programme. The TPB model posits that STs' future behaviour regarding inclusive PE lessons can be predicted using the degree to which: STs hold positive attitudes towards inclusive practice in PE (attitude); how others expect STs to include all children in PE lessons (subjective norm); and STs' beliefs about how able they are to perform this behaviour (perceived behavioural control). Four themes naturally emerged from the data: (1) understandings of inclusion in mainstream PE; (2) learned methods of including children with SEN in mainstream PE; (3) perceived barriers to inclusive practice; and (4) and the important role of professionals in inclusion. These themes will now be discussed in turn with reference to, when relevant, attitudes, subjective norm and perceived behavioural control.

\section{Understandings of inclusion in mainstream PE}

The Swiss participants perceived Ireland's inclusion practices to be more established than Switzerland's, "I think that inclusion is kind of new in Switzerland" (FG1 SS1) and "Ireland seems to be ahead of Switzerland regarding children with special needs; these children take part to the education system [sic], they have their own place in an ordinary class" (SSR). If correct we might assume, given an established practice of inclusion that the subjective norm in Ireland is to include children with SEN in PE lessons. How inclusion is understood, however, will affect how STs go about implementing this in practice.

During the first focus group interview, the younger second year Irish STs demonstrated only a surface level understanding of inclusion. Inclusion was simplistically defined as all children being involved in some way in a lesson, "I think inclusion is about making sure that everybody like the whole class is involved even like in their differences in ability" (FG1 IS3) and "Just try to make the children enjoy the lesson like each one as much as the other" (FG1 IS2). These participants observed that children with SEN are not experiencing a segregated education and therefore complying with the subjective norm of the country. Yet, this attitude to inclusion promotes only the integration of these children, representing an assimilation process through which children with SEN are required to fit into existing PE programmes (Fitzgerald et al, 2012; Fitzgerald, 2011; Hodge et al., 2004; Smith $\&$ Thomas, 2006). These sample quotes also highlight the emphasis Irish participants place on the importance of keeping children with SEN busy and happy in PE class rather than a consideration of learning outcomes. Previous research also suggests that practicing teachers' attitudes towards inclusion appear more in line with traditional conceptualisations of integration (Fitzgerald et al., 2012; Smith \& Green, 2004). This suggests that although there is perceived social pressure to include children with SEN in PE lessons in Ireland, the normative practice falls short of true inclusion.

The older Swiss Masters participants demonstrated a broader understanding of inclusion during the first focus group interview, with consideration for adaptations to teaching, learning outcomes and assessment, "The teacher must include every kid in the programme and adapt the material, the objective, the programme to include him in the group class" (FG1 SS1). This attitude towards inclusion moves beyond merely placing a child within a PE lesson, and beyond providing extra provision or individualised adjustments to support children with SEN. The Swiss participants seemed to understand inclusion as a process, one which is engaged in "through changes to various dimensions of a school's structure and practices" (Fitzgerald et al, 2012 p. 445). Although more progressive in their thinking the Swiss participants' understanding of inclusion still falls short of true inclusion. What remains lacking is an understanding of inclusion as a change in the physical, cultural and educational arrangements for the benefit of all children regardless of ability or disability status (Fitzgerald et al., 2012).

The exchange programme provided all participants the opportunity to observe different types of inclusive practice in action, "...we saw a broader image of what inclusion was" (FG3 IS3). The inter-country nature of the programme also afforded the opportunity for participants to observe inclusion in a country other than their own and exposed them to different cultural attitudes and 
practices with regards to inclusion. Following completion of the exchange, all participants perceived their level of understanding of inclusion to have improved, "I think that after being here [in Switzerland] ...we have a broader range of inclusion" (FG3 IS2). "This immersion, even short-lived, has enabled us to compare concretely the variety of teaching and the structures at the disposal of students and teachers" (SSR p. 3). Further data supporting this shift in understanding is reported in the themes that follow.

\section{Learned methods of including children with SEN in mainstream PE}

It is likely that this broader understanding of inclusive practice was influenced by the participants' observations of the behaviour of practicing teachers in both host countries. It was evident from focus group two that the Irish observations led to a better understanding of differentiation for PE. Participants discussed the various adaptations to lessons they observed which were successful in including children with SEN in mainstream PE lessons, “...even if you struggle jumping you can like walk or run and that's the way every kid gets to move, gets to do something so it's a broad range of activities. They do their own adaptation" (FG2 SS1) and "...like ball size, I had to make it easier, the ball would be bigger but to make it more challenging we had to use a smaller ball" (FG2 IS3).

It was clear from the data that the norm in Irish schools, where the observations took place, is differentiation for inclusion. In contrast, the data from focus group three (following the Swiss component of the exchange) suggested universal design is the norm in the Swiss schools observed. Participants talked about the use of equipment that was of benefit to all children regardless of ability. For example, one Irish ST noted that "The PE department in the school bought three chairs [wheelchair] identical the chair [sic] the student has to use during lessons so that other children could use them" (ISR IS1). Another observed that:

Children were also taking part in the high jump. I liked how the pole was plastic and didn't fall if it was hit as someone was jumping over. I thought this was a good idea as it eliminated failure and allowed the girl with the disability to fully take part. (ISR IS3)

The influence of culture on lesson content could be one possible explanation for the difference in inclusive practice reported. As one Swiss participant highlighted, “...people from Ireland like team sports compared to Switzerland where most people do individual sports like artistic gymnastic, ski or athletics" (SSR). The emphasis on team sports in Irish PE lessons is supported by existing literature (Woods, Tannehill, Quinlin, Moyna \& Walsh, 2010). Activities in PE that include an element of team play are considered problematic to inclusion when compared to more individual activities (Morley, Bailey, Tan \& Cooke, 2005), with children with SEN more often excluded from team games (Smith, 2004; Smith \& Green, 2004; Smith \& Thomas, 2006; Stafford, 1989). In Switzerland, Gasser et al., (2014) reported that kindergarten and elementary school children were more likely to opt for including children with disabilities into group activities in which group functioning was not too important. This argues for cooperative group activities which has implications for the PE programme and activities chosen. However, in their study, where the activities became athletic, demanding high levels of motor skill children were more selective in accepting children with SEN on board. Also in Switzerland, Weichert (2008) reported that communication and the type of working together between children and young people with or without a disability depends on the nature of the activity. Working together with a diverse audience develops relationships if the activity is less intensive and there is a small number of participants. Weichert (2008) believed that the type of activity influenced the level of communication and the degree of working together between children and young people with or without a disability. Working together with a diverse audience develops relationships if the activity is less intensive and there is a small number in a group. Thus, the focus on team sports as was evident in the school observations in Ireland may well serve to constrain the extent to which children with SEN can fully participate in PE lessons.

Supporting this, two lessons observed on the exchange which included elements of team play (one in each country) highlight constraints to inclusion. In Switzerland, the way a child with SEN 
was integrated into a team game fell short of inclusion due to lack of appropriate adaptations. One participant noted that "It was evident to see how a child with a disability can be excluded from a group, as during the team game, it was quite noticeable how the girl stood back and wasn't included by her peers" (ISR IS2) while another observed that "...because of the fact that she had Down syndrome she wasn't able to keep up with the rest of the [class]" (FG3 IS1). In Ireland there was evidence of segregation in team sports. The PE lesson observed in the mainstream second level school was "...an outdoor lesson for children with visual and physical impairments and also with autism" (SSR). Children in this school are educated according to academic ability, meaning that those with SEN tended to be educated together apart from their typically developing peers. Indeed, research suggests that there is a tendency for pupils with SEN to be excluded entirely from mainstream PE (Chandler \& Greene, 1995) or participate in PE lessons separately from more able peers (Hodge et al., 2004).

In the examples of practice provided by participants from both cohorts, the normative practices of PE were unaltered. It is interesting that participants failed to comment on the practice of the PE lesson or the curriculum as problematic, instead focusing on the inabilities of the children with SEN or their peers, a common practice by teachers as highlighted by Fitzgerald (2011) in her writing.

\section{Perceived barriers to inclusive practice}

Although positive attitudes play a significant role in explaining how teachers include children with SEN in PE lessons (Folsom-Meek \& Rizzo, 2002), according to the TPB, perceived competence is also linked to intentions to act (Ajzen \& Fishbein, 1980; Fishbein \& Ajzen, 1975; Folsom-Meek, Neary \& Krampf, 1995). This theme focuses on those STs' perceptions that negatively impact on perceived behavioural control, which will likely negatively impact inclusive practice going forward.

A number of teacher-related barriers to inclusion were highlighted by both cohorts of participants, illustrating perceptions of their own inadequacy in working with children with SEN. Concern relating to personal ability were most salient in focus group one, before the exchange programme, with participants referring to inadequate training, an emphasis on theory rather than practice at teacher education level, and insufficient knowledge of inclusive practices and SEN more generally "We don't learn enough about that [inclusion] so suddenly we're teachers and it might appear that you get to have a pupil with disabilities and you're not too sure what to do" (FG1 SS1); and:

Inclusion is difficult and that there's not enough practice and I think there is more and more disabilities...it's kind of difficult to know how to deal exactly with this one or with this child or with another one. (FG1 SS3).

The feelings of not knowing reflected in these participant quotes suggest participants lack the confidence and knowledge to adapt activities and include children with SEN in PE. The available literature suggests that these views are not uncommon. Both STs and practicing teachers report lacking confidence and feeling ill prepared to teach children with SEN (Crawford, 2011; Meegan \& MacPhail, 2006; Tindall et al., 2015; Travers et al., 2010; Vickerman, 2012; Vickerman \& Coates, 2009). These feelings have been linked in the literature to the extent to which STs feel they have been equipped to include children with SEN during their training (Morley et al., 2005; Wilkins \& Nietfield, 2004). Research suggests that most STs receive little SEN training (Smith \& Green, 2004) and insufficient training in the delivery of inclusive PE lessons (Crawford, 2011; Department of Education and Science, 1999).

A recent meta-analysis of the literature suggests that while PE teachers have a positive attitude towards inclusion, they are concerned about its practicality (Qi \& Ha, 2012). This has also been highlighted specifically within an Irish context (Marron et al, 2013). Research suggests that few STs are provided opportunities to observe PE lessons which include children with SEN (Vickerman, 2012). Indeed, in Ireland many teachers will not experience contact with children with SEN until they have begun employment (Travers et al. 2010). Research suggests STs who have a mix of theoretical input and practical experiences working with children with SEN were better prepared than STs who 
had not received this input to provide an inclusive learning environment (Conderman et al., 2013; Crawford et al., 2012; Sokal, Woloshyn \& Frank-Unrau, 2014; Tindall et al, 2016).

The value of practical experiences of including children with SEN in PE and observations of good practice in teacher education was recognised by participants. This is reflected in the following participant quotes: "Sitting down in a class [lecture] and reading a book and saying this, that and the other...if you're seeing it happening in a class then you're learning more about it" (FG3 IS1); "The experience on the ground proves to be the best way to experiment and exchange" (SSR); and "...when we're sitting in lectures and when we're learning about it and it's on a piece of paper it is completely different from when you get to see it in action" (FG2 IS1).

Indeed, the PE lesson observations in both host countries appeared to positively influence the confidence levels of participants as reflected in the quotes, "Just little things as to how to include her [pupil with disability on school visit] ... like it's small but it includes her so much but like little strategies that they can use" (FG2 IS3), "It would get [make] you think if I could do that, what else could you do?" (FG2 IS2) and:

...because I don't have any students including [children with SEN inclusion experience] so sometimes I'm a bit worried about how we can do and with Name [the teacher] and in

school it's like a really small adaptation and it worked like for including the child. FG2 SS1

The language used, exemplified in these two quotes, is interesting. The words "little" and "small" are used to describe the actions of the teacher suggesting it takes little effort for a large impact. This suggests that participants perceive inclusion as less daunting than before and provides evidence of increased perceived behavioural control. Indeed, some participants' confidence levels extended to the ability to critically assess the inclusion practices of the practicing PE teachers they observed, "I thought that the ball game could have been differentiated a little more as she [girl with Down syndrome] did not get the ball that often" (ISR IS1).

Despite participants appearing to gain confidence in inclusive practice, on completion of the exchange there was evidence of residual fear, related mostly to those barriers perceived to be outside of participants' direct control, "It would be great to do but when you have the small little pokey halls in Ireland you have the issue of space I think and we don't have the equipment either" (FG3 IS1).

Concerns about inadequate facilities and equipment are echoed in previous research (Hodge \& Akuffo, 2007; Lienert, Sherrill \&, Myers, 2001). Planning inclusive activities in PE often requires different equipment (Morley et al., 2005). Yet research suggests that specialist equipment for adaptations is often not readily available in schools (Crawford, 2011; Healy, 2013; Meegan \& MacPhail, 2006). Lack of equipment and outdated gymnasiums hinder a teacher's ability to provide opportunities for inclusion.

\section{The important role of professionals in inclusion}

The final theme emerging from these data concerned the important role of professionals in inclusion, specifically the role of the teacher and special needs assistants (SNAs). Research suggests that, in line with the subjective norm, STs understand their responsibility to teach PE to all children (Marron et al., 2013). Supporting this, following the European exchange programme, participants in this study demonstrated awareness of the role of the teacher in enhancing the experiences of all children in PE lessons. Participants spoke about the importance of making real connections with all children, regardless of ability, in order to promote learning, "I felt that she had a good relationship with all pupils and they responded well to her" (ISR IS2).

Participants also referred to teachers being active agents of change, "He was determined and he was kind of like standing up for the rights of like the child" (FG3 IS3) and "You have to be a manager teacher, you have to be a political teacher" (FG3 SS2). Teachers need to not only plan PE lessons to suit the abilities of all pupils in the class, but also lead a radical restructure of the culture of schools towards children with SEN through influencing policy, learning, teaching and assessment (Maher, 2016). Meeting teachers during the exchange who acted as child advocates seemed to empower participants, and on completion of the programme they suggested ways in which they too might 
actively fight to overcome perceived external barriers to inclusion and be leaders for change, "It was nice to see like all the equipment that we could try to push for when we're teachers to get in our schools" (FG3 IS2) and "It showed me how when I become a qualified teacher I too will be able to make a difference" (ISR IS3). A Swiss student realised that inclusive pedagogy may involve contact with other professionals beyond the gym "You have to speak with political [politicians], you have to speak with the boss [school principal]" (FG3 SS2).

Participants also talked of using teacher aides or SNAs as a method of facilitating inclusion in PE, "...have help with assistants" (FG1 SS2) and "He joined in all the lessons with the help of an SNA" (ISR IS1). Indeed, previous research has reported that having an SNA in a PE lesson is the most common modification teachers make to accommodate children with SEN (Crawford, 2011). In a Swiss context, Gasser et al. (2014) also highlighted this additional support to the class teacher, and to individuals with SEN. Research suggests, however, that an SNA's time tends to be prioritised for the subjects of English, Maths and Science, or for lunch (Marron et al., 2013) with very few SNA resources being allocated to PE (Maher, 2016; Maher \& Macbeth, 2014). This makes it unlikely participants will have reliable assistance from SNAs for PE lessons.

When an SNA is available to support the teacher in PE, however, it is also important that their presence does not let the teacher take his or her focus from being responsible with regards to modifying lessons for inclusive practice (Lieberman, 2007; Smith \& Thomas, 2006). In addition to the fact that the majority of SNAs have not received any PE specific training, the presence of SNAs in PE lessons can have a detrimental effect on the learning and social interaction of pupils with SEN (Maher, 2016; Maher \& Macbeth, 2014; Logan, 2006; Smith \&Thomas, 2006). A recent meta-analysis of the literature suggests children with SEN tend to interact socially more with their SNAs during PE classes than with their peers (Haegele \& Sutherland, 2015). Thus, although having an SNA in the lesson may increase a teacher's perceived behavioural control, the overreliance of the teacher on an SNA for inclusion may mean that the child is socially isolated (Logan, 2006; Place \& Hodge, 2001), and reinforce barriers between those with and without SEN (Maher, 2016; Maher \& Macbeth, 2014).

\section{Discussion}

The TPB is used to measure an individual's intent to perform a behaviour which indicates the likelihood of that behaviour occurring. The three components of this theory are attitudes, subjective norm, and perceived behavioural control. This research suggests that the subjective norm towards inclusion in PE lessons can be country dependent. The data in this study suggests that inclusion in Ireland, although more of an established practice, relies heavily on differentiation techniques. In contrast, lessons in Switzerland observed in this study demonstrated more of a universal design approach to inclusion. These cultural differences were reflected in participants' reported understandings of inclusion before the exchange and pointed towards the type of inclusion these STs would be expected to perform once employed.

Teaching education universities should be mindful of the expectations and practices with regards to inclusion within their respective countries and provide opportunities for their STs to critically question these norms. One such method, recommended based on the results of this study, is a cultural exchange. The opportunity to compare inclusive practice in two different countries brought the subjective norm into consciousness for participants in this study and facilitated critical questioning of this norm. Findings therefore highlight the benefits to including intercultural opportunities into teacher education specifically for PE teachers, a finding that is also supported by past research (European Agency for Development in Special Needs Education, 2010; Goodwin, 2010; Ko, Boswell and Yoon, 2015).

The results of this study further suggest that STs' attitudes and perceived behavioural control towards inclusion in PE can be positively influenced by direct observation of inclusive PE lessons. All participants appeared to gain a greater understanding of inclusion because of participation in this study. Findings suggest participants grasped the concept of differentiation by the end of the exchange. In both the focus groups and report data, participants referred to the benefits of making adaptations to PE activities to better include children with SEN. There appeared less understanding 
of universal design strategies for inclusion. Although Ireland may have a more developed framework for inclusive practice, the study highlights a need to now develop and progress towards an increased emphasis on universal design for inclusion at both teacher education and in-service education in Ireland.

The overreliance in Ireland to date on differentiation techniques for inclusion could be due in part to a focus on team games. Indeed, research suggests that in Ireland team sports and games dominate the PE curriculum in practice (Woods et al., 2010). It is recommended that further emphasis is placed on the inclusion of individual sports and activities in PE at teacher education level in Ireland.

The lived experience afforded was positively received by participants in this study who had noted an over-reliance on theory within their education courses. This finding is in line with other research (Crawford, 2011; Hardin, 2005; Meegan \& MacPhail, 2006; Morley et al., 2005; Piletic \& Davis, 2010; Rovegno \& Dolly, 2006; Tindall et al., 2016; Tsangaridou, 2006). This finding suggests teacher educators should provide STs with practical learning experiences to promote positive thinking towards inclusion in PE lessons and to seek and embrace an intercultural exchange for STs and lecturers.

\section{Limitations and recommendations}

It is important to acknowledge the limitations of this study. Participant STs represent a very small proportion of a cohort of students in both Universities. This study provides one detailed example to highlight an opportunity that was designed to expose STs to inclusive practice, building on STs' core inclusion modules and lectures, to impact their in-service inclusive practice. Due to the small number of participants in this study, comparisons could not be made based on previous teaching experience. Future research should focus on determining how previous teaching experience influences inclusive practice and attitudes towards the same. A further limitation is that the researchers conducting the focus groups were also the participants' lecturers. The extent to which this influenced the information provided by participants in the groups is unknown. In relation to the data collection and the reports used, the variations in the reporting systems required by the universities (Irish STs' individual reflections and Swiss ST collaborative report) is recognised as a design flaw. Finally, it may have been challenging for the Swiss STs to convey their points in the focus groups with complete clarity due to English being their second language. Nevertheless, this study makes a unique contribution to the existing literature and has important implications for practice as previously outlined.

\section{Perspectives}

The TPB model was used in this study to provide a voice to STs' understandings of inclusion in PE lessons. The observations increased perceived behavioural control at a personal level. There was evidence of increased consideration of learning outcomes for children with SEN in PE and participants' own accountability for inclusion. Despite this, perceived external barriers, such as access to appropriate equipment and resources, remained following completion of the exchange. This suggests that further intervention is needed in teacher education to overcome barriers deemed outside of STs' control. The findings point to the benefits of vicarious experiences and exposing STs to positive role models. Participants reported being empowered to lobby for supports for inclusion in PE after observing teachers who advocate on behalf of their pupils with SEN for resources.

This research adds to the Irish research of Tindall and colleagues (2016) and Crawford and colleagues (2012) and to international research on ST education for PE inclusive practices. The findings suggest that a short European exchange programme with a focus on observation of inclusive practices can impact STs' perspectives for future meaningful inclusive practice, to achieve positive PE outcomes for all children in PE lessons and to promote active and healthy lifestyles.

\footnotetext{
Author affiliations:

1 Dublin City University; susan.marron@dcu.ie

2 University College Dublin; sonia.morris@ucdconnect.ie
} 
* Correspondence: susan.marron@dcu.ie; Tel.: +353868842346

Author Contributions: Conceptualization: Susan Marron, Data Collection: Susan Marron, Data Analysis: Sonia Morris and Susan Marron, Write Up: Sonia Morris and Susan Marron, Reviewing: Sonia Morris and Susan Marron

Funding: This research received no external funding

Acknowledgments: The authors would like to acknowledge the contribution of Magali Desoeudres, lecturer at the haute école pédagogique, University of the State of Vaud, Lausanne, Switzerland, for her work and hospitality on the exchange programme. We thank the schools in Dublin and Lausanne for their support. Finally, we thank the student teacher participants in the research study. The research reported here was conducted under the CREATE21 programme (Collaborative Research Across Teacher Education) Institute of Education http://www.dcu.ie/create21/About-create21.shtml.

Conflicts of Interest: The authors declare no conflict of interest.

\section{References}

Ajzen, I., \& Fishbein, M. (1980). Understanding attitudes and predicting social behaviour. Englewood Cliffs, NJ: Prentice-Hall.

Block, M. E. (2007). A teachers' guide to including children with disabilities into general physical education (3rd ed.). Baltimore MD: Paul H. Brookes Publishing.

Cardona, C. (2009). Teacher education students' beliefs of inclusion and perceived competence to teach students with disabilities in Spain. Journal of the International Association of Special Education, 10(1), 33-41. doi:10.1123/apaq.2013-0112

Chandler, J. P., \& Greene, J. L. (1995). A State-wide survey of adapted physical education service delivery and teacher in-service training. Adapted Physical Education Quarterly, 12(3), 262-274.

Conderman, G., Johnston-Rodriguez, S., Hartman, P., \& Walker, D. (2013). Honoring voices from beginning special educators for making changes in teacher preparation. Teacher and Special Education, 36(1), 65-76. doi:10.1177/0888406412473311

Crawford, S. (2011). An examination of current adapted physical activity provision in primary and special school in Ireland. European Physical Education Review, 17(1), 91-109. doi:10.1177/1356336X11402260

Crawford, S., O’Reilly, R., \& Flanagan, N. (2012). Examining current provision, practice and experience of initial teacher providers in Ireland preparing pre-service teachers for the inclusion of students with special educational needs in physical education classes. European Journal of Adapted Physical Activity, 5(2), $23-$ 44. doi:10.1177\%2F1356336X11402260

Department of Education and Science. (1999). Report of the people with a disability in sport taskforce. Dublin, Ireland: Government of Ireland.

Etienne, R., Parkinson, S., \& Verkest, H. (2005). Citizenship education and the inclusion of vulnerable young people. London: CiCe Network.

European Agency for Special Needs and Inclusive Education. (2010). Teacher education for inclusion: International literature review. Odense, Denmark: European Agency for Development in Special Needs Education. Retrieved from https://www.european-agency.org/sites/default/files/TE4I-LiteratureReview.pdf

Fishbein, M. A., I. (1975). Belief, attitude, intention and behaviour: An introduction to theory and research. Reading, MA: Addison-Wesley.

Fitzgerald, H. (2011). "Drawing" on disabled students' experiences of physical education and stakeholder responses. Sport, Education and Society, (iFirst Article), 1-20. doi:10.1080/13573322.2011.609290

Fitzgerald, H., Stride, A., \& Jobling, A. (2012). Inclusivity and research: Capturing the lived experience of young people with disabilities. In D. Moore, A. Gorra, M. Adams, J. Reaney \& H. Smith (Eds), Disabled students in education: Technology, transition, and inclusivity (pp. 272-287). PA, USA: Hersey.

Florian, L., \& Rouse, M. (2009). The inclusive practice project in Scotland: Teacher education for inclusive education. Teaching and Teacher Education, 25(4), 594-601. doi:10.1016/j.tate.2009.02.003

Folsom-Meek, S. L., Nearing, R. J., \& Krampf, H. (1995). Relationships between preservice physical education teacher attributes and attitude towards students with mild disabilities. In Research Quarterly for Exercise and Sport 66 (Suppl.). Québec City.

Folsom-Meek, S. L., \& Rizzo, T. L. (2002). Validating the physical educators' attitude toward teaching individual with disabilities III (PEATID III) survey for future professionals. Adapted Physical Activity Quarterly, 19(2), 141-154. doi:10.1123/apaq.19.2.141 
Gasser, L., Malti, T., \& Buholzer, A. (2014). Swiss children's moral and psychological judgements about inclusion and exclusion of children with disabilities. Child Development, 85(2), 532-548. http://psycnet.apa.org/doi/10.1111/cdev.12124

Department of Education and Science. (1999). Physical education curriculum teacher guidelines. Dublin, Ireland: Stationary Office

Haegele, J. A., \& Sutherland, S. (2015). Perspectives of students with disabilities toward physical education: A qualitative inquiry review. Quest, 67(3), 255-273. doi:10.1080/00336297

Häusermann, S. (2014). Sport et handicap: Pistes pour une pratique sportive commune. Macolin: Office Fédéral du Sport.

Hardman, M. (2009). Redesigning the preparation of all teachers within the framework of an integrated program model. Teacher and Teaching Education, 25(4), 583-587. doi:10.1016/j.tate.2099.02.005

Healy, S. (2013). Adapting equipment for teaching object control skills. Palaestra, 27(4) 37-42.

Hodge, S., Ammah, J., Casebolt, K., LaMaster, K., \& O'Sullivan, M. (2004). High school general physical education teachers' behaviours and beliefs associated with inclusion. Sport, Education and Society, 9(3), 395-420. doi:10.1080/13573320412331302458

Hodge, S. R., \& Akuffo, P. B. (2007). Adapted physical education teachers' concerns in teaching students with disabilities in an urban pacific school district. International Journal of Disability, Development and Education, 54(4), 399-416. doi:10.1080/10349120701654571

Jeong, M., \& Block, M. (2011). Physical education teachers' beliefs and intentions toward teaching students with disabilities. Research Quarterly for Exercise and Sport, 82(2), 239-246. doi:10.1080/02701367.2011.10599751

Ko, B., Boswell, B., \& Yoon, S. (2015). Developing intercultural competence through global link experiences in physical education. Physical Education and Sport Pedagogy, 20(4), 366-380. doi:10.1080/17408989.2013.837441

Liberman, L. and AAPAR. (2007). Para-educators in Physical Education, US: Human Kinetics.

Lienert, C., Sherrill, C., \& Myers, B. (2001). Physical educators' concerns about integrating children with disabilities: A cross-cultural comparison. Adapted Physical Activity Quarterly, 18(1), 1-17.

Logan, A. (2006). The role of special needs assistants supporting students with special educational needs in Irish mainstream primary schools. Support for Learning, 21(2), 92-99. doi:10.1111/j.1467-9604.2006.00410.x

Maher, A. J. (2016). Special educational needs in mainstream secondary school physical education: Learning support assistants have their say. Sport, Education and Society, 21(2), 262-278. doi:10.1080/13573322.2014.905464

Maher, A., \& Macbeth, J. (2014). Physical education, resources and training: The perspective of special educational needs coordinators working in secondary schools in North-West England. European Physical Education Review, 21(1), 90-103. doi:10.1177/1356336X13496003

Marron, S., Murphy, F., \& O’Keeffe, M. (2013). Providing “good day" physical education experiences for children with SEN in mainstream Irish primary schools. REACH Journal of Special Needs Education in Ireland, 26(2) 92-103. doi:10.1177/1356336X06060213

Meegan, S. and MacPhail, A. (2006). Irish physical educators' attitude toward students with special educational needs. European Physical Education Review, 2(1), 75-97. doi:10.1177\%2F1356336X06060213

Meyers, S., \& Lester, D. (2013). The effects of situated learning through a community partnership in a teacher preparation program. SAGE Open, July-September 1-9 doi:10.1177/2158244013497025

Morley, D., Bailey, R., Tan, J., \& Cooke, B. (2005). Inclusive physical education: Teachers' views of teaching children with special educational needs and/or disabilities in physical education. European Physical Education Review, 11(1), 84-107. doi:10.1177/1356336X05049826

Pédagogie différenciée, chapitre IX, Art. 98 (2011). Loi sur l'enseignement obligatoire (LEO) [Differentiated pedagogy, Law on Obligarory schooling]. Retrieved from https://www.vd.ch/fileadmin/user_upload/themes/formation/sante_scolaire/fichiers_pdf/Loi_sur_1_enseig nement_obligatoire_LEEO_.pdf

Piletic, C., \& Davis, R. (2010). A profile of the introduction to adapted physical education course within undergraduate physical education teacher education programs. ICHPER-SD Journal of Research, 5(2), 2632.

Place, K., \& Hodge, S. R. (2001). Social inclusion of students with physical disabilities in general physical education: A behavioural analysis. Adapted Physical Activity Quarterly, 18(4), 389-404.

Qi, J., \& Ha, A. (2012). Inclusion in physical education: A review of literature. International Journal of Disability, Development and Education, 59(3), 257-281. doi:10.1080/1034912X.2012.697737

Rovegno, I., Dolly, J. (2006). Constructivist perspectives on learning. In D. Kirk, D. MacDonald \& M. O'Sullivan (Eds.), The Handbook of Physical Education (1st ed., Vols. 1-Book, Section, pp. 312-324). London: Sage. 
Rust, R., \& Sinelnikov, O. A. (2010). Practicum in a self-contained environment: Pre-service teacher perceptions of teaching students with disabilities. The Physical Educator, 67(1) 33-45.

Smith, A., \& Green, K. (2004). Including pupils with special educational needs in secondary school physical education: A sociological analysis of teachers' views. British Journal of Sociology of Education, 25(5), 593608. doi:10.1080/0142569042000252080

Smith, A., \& Thomas, N. (2005). Inclusion, special educational needs, disability and physical education. In K. Green \& K. Hardman (Eds.), Physical education, essential issues (Vols. 1-Book, Section, pp. 220-238). London: Sage.

Smith, A., \& Thomas, N. (2006). Including pupils with special educational needs and disabilities in national curriculum physical education: A brief review. European Journal of Special Needs Education, 21(1), 69-83. doi:10.1080/08856250500491849

Sokal, L., Woloshyn, D., \& Frank-Unrau, S. (2014). How important is practicum to pre-service teacher development for inclusive teaching? Effects on efficacy in classroom management. Alberta Journal of Educational Research, 59(2), 285-298.

Stafford, I. (1989). Everybody active: A sports council national demonstration project in England. Adapted Physical Activity Quarterly, 6(2), 100-108.

Taliaferro, A., Hammond, L., \& Wyant, K. (2015). Preservice physical educators' self- efficacy beliefs toward inclusion: The impact of coursework and practicum. Adapted Physical Activity Quarterly, 32(1), 49-67. doi:10.1123/apaq.2013-0112

Tindall, D., Culhane, M., \& Foley, J. (2016). Pre-service teachers' self-efficacy towards children with disabilities: An Irish perspective. European Journal of Adapted Physical Activity, 9(1), 27-39.

Tindall, D., MacDonald, W., Carroll, E., \& Moody, B. (2015). Pre-service teachers' attitudes towards children with disabilities: An Irish perspective. European Physical Education Review, 21(2) 206-221. doi:10.1177/1356336X14556861

Travers, J., Balfe, T., Butler, C., Day, T., Dupont, M., McDaid, R., Prunty, A. (2010). Addressing the challenges and barriers to inclusion in Irish schools: Report to research and development committee in the Department of Education and Skills. Dublin, Ireland: St. Patrick's College.

Tsangaridou, N. (2006). Teachers knowledge. In D. Kirk, D. MacDonald \& M. O'Sullivan (Eds.), The handbook of physical education (1st ed., Vols. 1-Book, Section, pp. 502-515). London: Sage Publications.

UNESCO. (2014). World-wide survey of school physical education. Paris: United Nations Educational, Scientific and Cultural Organization. Retrieved from http://unesdoc.unesco.org/images/0022/002293/229335e.pdf

United Nations General Assembly. (2007). Convention on the rights of persons with disabilities: Resolution/adopted by the General Assembly, 24 January 2007, A/RES/61/106, http://www.refworld.org/docid/45f973632.html [accessed 24 May 2016], (Laws/Statutes).

Vickerman, P. (2012). Including children with special educational needs in physical education: Has entitlement and accessibility been realised? Disability \& Society, 27(2), 249-262. doi:10.1080/09687599.2011.644934

Vickerman, P., \& Coates, J. K. (2009). Trainee and recently qualified physical education teacher's perspectives on including children with special educational needs. Physical Education and Sport Pedagogy, 14(2), 137-153. doi:10.1080/17408980802400502

Weichert, W. (2008). Integration durch Bewegungsbeziehungen. Baltmannsweiler: Schneider Verlag Hohengehren. In F. Fediuk (Ed.), Inklusion als bewegungspädagogische Aufgabe (Vols. 1-Book, Section, pp. 55-95). Schneider Verlag Hohengehren: Baltmannsweiler.

Wilkins, T., \& Nietfield, J. (2004). The effect of a school-wide inclusion training programme upon teachers' attitudes about inclusion. Journal of Research in Special Educational Needs, 4(3), 115-121. doi:10.1111/j.1471-3802.2004.00026.x

Winter, E., \& O' Raw, P. (2010). Literature review of the principles and practices relating to inclusive education for children with special educational needs. Meath, Ireland: National Council for Special Education.

Woods, C., Tannehill, D., Quinlan, A., Moyna. N., \& Walsh, J. (2010). The children's sport participation and physical activity study. Dublin, Ireland: School of Health and Human Performance, DCU and the Sports Council.

Wright, H., \& Sugden, D. (1999). Physical education for all: Developing physical education in the curriculum for pupils with special educational needs. London: David Fulton..

(C) 2018 by the authors. Submitted for possible open access publication under the terms and conditions of the Creative Commons Attribution (CC BY) license (http://creativecommons.org/licenses/by/4.0/). 